\title{
Twitter, internautas
}

vecinos y los intersticios de la polarización política

Un estudio centrado en la campaña electoral de 2019 en el Partido de General Pueyrredon, Argentina ${ }^{1}$

Twitter, neighboring Internet users and the local interstices of political polarization

A study focused on the 2019 electoral campaign in the Party of General Pueyrredon, Argentina

Twitter, internautas vizinhos e os interstícios locais da polarização

política

Um estudo focado na campanha eleitoral de 2019 no Partido do General Pueyrredon, Argentina

DOI: https://www.doi.org/10.18861/ic.2021.16.2.3163

\section{WANDA JUARES}

wandajuares@gmail.com - Universidad Nacional de Mar del Plata, Argentina.

ORCID: https://orcid.org/0000-0002-5329-6947

\section{- SILVANA FERREYRA}

silvanaferreyra82@gmail.com - Universidad Nacional de Mar del Plata, Argentina.

ORCID: https://orcid.org/0000-0002-4631-5273

1 Respecto al título del artículo, y específicamente a la noción de internautas vecinos, aclaramos lo siguiente: en español, el género masculino en singular y plural incluye ambos géneros. Esta forma propia de la lengua oculta la mención de lo femenino y las identidades no binarias. No obstante, atentas a las sugerencias de los editores sobre las dificultades en la lectura que ocasiona el uso explícito de ambos géneros o la adopción de formas inclusivas ( $\mathrm{x}, \mathrm{e}, @)$, hemos adoptado el empleo del masculino, aclarando que supone referirse, en lo sucesivo, a internautxs, candidatx, usuarixs, según el caso. 
CÓMO CITAR: Juares, W. \& Ferreyra, S. (2021). Twitter, internautas vecinos y los intersticios de la polarización política. Un estudio centrado en la campaña electoral de 2019 en el Partido de General Pueyrredon, Argentina. InMediaciones de la Comunicación, 16(2), 103-129. DOI: https://www.doi. org/10.18861/ic.2021.16.2.3163

Fecha de recepción: 10 de marzo de 2021

Fecha de aceptación: 23 de junio de 2021

\section{RESUMEN}

Las redes sociales muestran que el espacio público virtual puede deconstruirse en una multiplicidad de esferas. Para algunas lecturas, esa fragmentación fomenta la polarización y reproduce las llamadas "cámaras de eco". Desde otras ópticas, la superposición de públicos es lo que habilita la circulación de los mensajes. Siguiendo esta última línea, este artículo propone un análisis de los internautas que siguieron por Twitter a los candidatos a Intendente en el Partido de General Pueyrredon (Argentina) durante la campaña electoral de 2019. A partir de allí, nos proponemos abrir algunas líneas de reflexión acerca del debate sobre las limitaciones o las capacidades democráticas del espacio público virtual. Nuestra hipótesis es que existe un espacio público virtual local poblado por un tipo de usuarios -al que denominamos internautas vecinos-que puedepensarse comouna suerte de intersticio subnacional, en el marco de la polarización política reinante a nivel país. Para el seguimiento y el análisis de los internautas se utilizó el lenguaje R. En primer lugar, reconstruimos el corpus de "seguidores" mediante la elaboración de una base de datos que nos permite identificar cercanías y distancias entre ellos en el mapa político. En segundo término, visualizamos y analizamos las palabras más frecuentes en las biografías de los seguidores de los candidatos para identificar manifestaciones que trasciendanlas comunidades políticas o ideológicas.

PALABRAS CLAVES: esfera pública virtual, campañas electorales, sociología digital, Twitter, subnacional.

\section{ABSTRACT}

Social networks show that the virtual public space can be deconstructed in a multiplicity of spheres. For some readings, that fragmentation encourages polarization and reproduces the so-called echo chambers. From other perspectives, the overlapping of audiences is what enables the circulation of messages. Following this last line, the article focuses on a specific analysis, focused on Internet users who followed the candidates for Mayor in the General Pueyrredon Party (Argentina) on Twitter during the 2019 electoral campaign. From there, we propose to open somelines of reflection about the debate on the limitations or democratic capacities of virtual public space. Our hypothesis is that there is a local virtual public space populated by a type of users -which we call neighboring Internet users- that can be thought of as a kind of sub-national interstice within the framework of the prevailing political polarization at the country level. For the follow-up and analysis of the Internet users, the $\mathrm{R}$ software was used. Firstly, we reconstructed the corpus of followers by creating a database that allows us to identify neighborhoods and distances on the political map. Secondly, we visualized and analyzed the most frequent words in the biographies of the political candidates followers.

KEYWORDS: virtual public sphere, electoral campaigns, digital sociology, Twitter, subnational.

\section{RESUMO}

As redes sociais mostram que o espaço público virtual pode ser desconstruído em uma multiplicidade de esferas. Para algumas leituras, essa fragmentação estimula a polarização e reproduz as chamadas câmaras de eco. Sob outros pontos de vista, a sobreposição de públicosé o que possibilita a circulação das mensagens. Seguindo esta última linha, o artigo concentra-se numa análise específica, focada nos internautas que acompanharam os candidatos a prefeito do Partido General Pueyrredon (Argentina) pelo Twitter durante a campanha eleitoral de 2019. A partir daí, propomos abrir algumas linhas de reflexão sobre o debate das limitações ou capacidades democráticas do espaço público virtual. Nossa hipótese é que existe um espaço público virtual local povoado por um tipo de usuários -que denominamos internautas vizinhos- que pode ser pensado como uma espécie de interstício subnacional no quadro da polarização política prevalecente em nível nacional. Para o acompanhamento e análise dos internautas, foi utilizado o software R. Primeiramente, reconstruímos o corpus de "seguidores" criando um banco de dados que nos permite identificar aproximações e distâncias no mapa político. Em segundo lugar, visualizamos e analisamos as palavras mais frequentes nas biografias dos seguidores dos candidatos políticos.

PALAVRAS-CHAVE: esfera pública virtual, campanhas eleitorais, sociologia digital, Twitter, subnacional. 


\section{INTRODUCCIÓN}

En este artículo nos concentramos en el análisis del uso de Twitter en la campaña electoral para elegir intendente en el Partido de General Pueyrredon (PGP), Argentina, durante el año 2019. En tal sentido, y focalizado el interés en un caso particular, nos preguntamos cuáles son los intersticios que puede abrir la política local para pensar una red de asociaciones más generales a la hora de reflexionar sobre estos nuevos modos de comunicación política. De allí que seguimos las sugerencias de Coleman (2010), quien refiere a la importancia de "provincializar" los medios digitales, recorte que no significa negar su alcance global, sino considerar la forma específica en que estos medios se han convertido en el centro de la articulación de las creencias, prácticas, rituales y modos de estar en el mundo.

El artículo se inscribe así y buscar aportar al debate actual sobre los cambios que se están produciendo en elámbito dela participación política online, y cómo estos inciden en la configuración de la esfera pública. Papacharissi (2002) retoma las concepciones de esfera pública propuestas por Habermas, pero también por sus críticos, y se pregunta si Internet puede ayudar a crear una nueva esfera pública, fomentar diversos espacios públicos o simplemente ser absorbida por la cultura empresarial hegemónica en el capitalismo de plataformas (Srnicek, 2018). En ese marco, un aspecto que destaca Papacharissi es la constitución de ámbitos de discusión online que, si bien trascienden fronteras geográficas, no son permeables entre sía nivel político eideológico, y que dan lugar al fenómeno de la polarización y fragmentación que caracterizaría a Internet.

En efecto, en los últimos años ha crecido el consenso académico en torno a las redes sociales como una "cámara de eco" o una "burbuja de filtro" en donde los flujos informativos que cada usuario genera y obtiene son coincidentes con sus posicionamientos, creencias y prejuicios (Calvo, 2015; Pariser, 2011; Barberá et al., 2015; Calvo \& Aruguete, 2020). Para el caso concreto de los estudios de campañas electorales, donde los mensajes procuran convencer al electorado flotante, parece todavía más relevante preguntarse si el fenómeno de la polarización política no deja intersticios y, en ese caso, si las redes sólo se limitan a reforzar comunidades de adeptos. En tal sentido, entendemos que la cercanía de la escena política local puede ser propicia para mostrar cómo algunas plataformas todavía puedan generar espacios de interacción dinámica y horizontal entre políticos y ciudadanos. Lejos de las utopías democratizadoras que se sembraron en sus orígenes, las plataformas podrían seguir siendo -al menos- espacios de mediación e interacción más dinámicas.

En ese sentido, Bruns y Highfield (2018) proponen una mirada particular acerca de la problemática de la segmentación y promueven investigaciones localizadas que nos permitan identificar las distintas partes interconectadas de una esfera pública virtual, a la que consideran nueva y multifacética, para así 
equilibrar los esquematismos que promuevela polarización del debate público. De acuerdo con esta propuesta, al deconstruir la esfera pública tradicional en una serie de public sphericule o micro-públicos, es posible observar que ninguno de ellos es mutuamente excluyente, a la vez que coexisten, se cruzan y se superponen en múltiples formas. Tomando la referencia de Twitter, es posible observar que existen redes egocentradas alrededor de cada perfil de usuario, lo que puede considerarse como un público personal. Así, la multitud de públicos personales, superpuestos entre sí, permiten flujos de información que están determinados por identidades sociodemográficas comunes, intereses de actualidad y prácticas de comunicación entre los usuarios. En combinación, constituyen un mosaico global de micropúblicos interconectados, uniendo medios, interacciones cara a cara y otras formas y canales de comunicación, que pueden verse como la base de la esfera pública en general (Bruns \& Highfield, 2018). A partir de esta propuesta teórica es que nos preguntamos: ¿No podrían identificarse esos solapamientos poniendo el foco en los distintos niveles (nacional, provincial, municipal) de la campaña política en redes? ¿Cómo modifica este enfoque y la noción de público personal nuestra perspectiva sobre lo que significa "seguir" a un político?

Desde otro enfoque, centrado en los modos de interpelación que despliegan los políticos en las redes sociales, la investigación de Slimovich (2018a) sobre la mediatización del expresidente argentino Mauricio Macri², también busca apartarse de los planteos centrados en la polarización. En esta clave, la autora propone tres categorías para dar cuenta sobre las distintas posibles formas de estar en la red: internautas-seguidores, internautas-indecisos, internautas-opositores. Estas nociones son imaginadas en correlato con las figuras del prodestinatario, el paradestinatario y el contradestinatario retomadas de las teorizaciones de Eliseo Verón sobre el discurso político.

A modo de hipótesis, en este artículo postulamos la existencia de un espacio público virtual local ${ }^{3}$ poblado por una variante del internauta indeciso, al que denominaremos internauta vecino. A partir de esta última categoría, buscamos referenciar una identidad territorial común, a la par que referir a la distinción entre vecinos y ciudadanos, frecuente para distinguir al electorado en distintos niveles administrativos. En cuanto a los internautas vecinos, se pudo determinar que durante la campaña electoral a intendente en el municipio de General Pueyrredon siguieron en Twitter a distintos candidatos. Estos solapamientos garantizaron la circulación de información entre múltiples micro-públicos y se constituyeron en una suerte de espacio público virtual local, un intersticio que permite escapar (aunque sea fugazmente) a la dinámica de polarización política característica de los flujos de discusión reinante a nivel país.

2 Macri fue presidente de Argentina entre 2015 y 2019 representando a la alianza política Cambiemos.

3 En términos de Papacharissi: "Un espacio virtual mejora la discusión; una esfera virtual mejora la democracia" (2002, p. 11). 
Para demostrar nuestra tesis, proponemos entonces dos movimientos complementarios. Por un lado, corremos el foco de las contiendas nacionales hacia una disputa electoral del ámbito local. Por otro, no nos concentramos en los perfiles de Twitter de los candidatos, sino en sus "seguidores". Calvo (6 de marzo de 2014), en un texto titulado "Un cafecito para Scioli", reconstruye el espacio político de Twitter en Argentina (izquierda-derecha, peronismoantiperonismo) utilizando las listas de "amigos" de 99 cuentas de políticos. El cruce entre amigos le permite medir el grado de afinidad entre ellos y, luego, volcar esas coordenadas para graficar el mapa político. Aquí recuperamos dicha apuesta metodológica para la campaña electoral que tuvo lugar en General Pueyrredon, aunque en nuestro caso para observar las afinidades a partir del cruce de seguidores. A diferencia del análisis de los amigos, los resultados del cruce de seguidores entre los candidatos permiten demostrar algunas superposiciones no consistentes con las preferencias ideológicas.

En resumen, entendemos que el análisis de una campaña local desde la perspectiva de los seguidores de los políticos puede ser un doble desplazamiento oportuno para indagar en torno a las limitaciones o las capacidades democráticas del espacio público virtual. En los primeros apartados revisaremos la literatura que problematiza el modo de emergencia del discurso político en Twitter en la Argentina, los estudios que reflexionan sobre las características de seguidores e internautas, y daremos cuenta de la metodología y el diseño de la investigación realizada para este artículo. Luego se desarrollará el análisis concreto a partir de la utilización del lenguaje de programación $\mathrm{R}$-básicamente, un lenguaje de programación con un enfoque al análisis estadístico-. En esa dirección, se trabajó en la elaboración de una base de datos que nos permite identificar solapamientos entre seguidores de los distintos candidatos a intendente y se hizo uso de técnicas de minería de textos-específicamente la herramienta frecuencias de palabras-para identificar recurrencias y narrativas en las biografías de los usuarios.

\section{ESTADO DEL ARTE}

Los constantes cambios en las prácticas culturales mediadas por las tecnologías conllevan transformaciones en nuestras experiencias, vivencias y sensibilidades como sujetos sociales. La penetración de las plataformas de redes sociales en la cotidianeidad de los sujetos, la ampliación de servicios de Internet y la proliferación de dispositivos portátiles como celulares y smartphones transformaron las interacciones sociales de forma acelerada. Van Dijck (2016) caracteriza el entramado de medios conectivos y nuevas sociabilidades como una cultura de la conectividad, conformada por un ecosistema tecnocultural de carácter cambiante en donde el desarrollo tecnológico, las empresas y los usuarios coevolucionan constantemente. Siguiendo esta línea, definimos a las 
plataformas como constructos tecnoculturales en donde se despliegan y se performan actividades sociales mediadas por la arquitectura computacional, los algoritmos, las capacidades de acción/creación de los usuarios y las condiciones particulares de cada servicio.

Ante este escenario sociotécnico (Callon, 2013; Latour, 2008), en tanto red de humanos y artefactos tecnológicos, el campo de la sociología política aparece como un ámbito vital para la indagación de temáticas relacionadas, como es nuestro caso, a las prácticas de comunicación política, las interacciones entre políticos-ciudadanos, las formas de acción y participación, el espacioylas nuevas formas de sociabilidad y la convergencia entre viejos y nuevos medios, que emergen como categorías que se recrean en torno a los entramados que impone la utilización de la web 2.0.

En este marco, el análisis de las campañas electorales, su despliegue en entornos virtuales y la datificación han sido áreas de estudio más avanzadas y atravesadas por problemáticas asociadas al marketing político, la sociología, la comunicación y las ciencias políticas (Criado, Martínez-Fuentes \& Silván, 2012; Congosto, 2015; Ventura, 2018; Galup, 2019). Por su parte, la elección de la plataforma virtual Twitter para el estudio de las campañas radica en las posibilidades para acceder a la información y la importancia que se le ha dado a esta red como parte de las estrategias políticas y como plataforma para la búsqueda de relaciones entre los actores políticos y los usuarios. Respecto al escenario argentino, hay un acuerdo extendido en fechar la digitalización de la política en la campaña presidencial del 2011, la cual dio lugar a diversos estudios sobre comunicación política, discurso y estrategias argumentativas delos candidatos (Sarlo, 2011; Castelo, 2014; Ventura, 2016; Annunziata, Ariza \& March, 2017).

Las redes sociales, a diferencia del espacio mediático tradicional, habilitan nuevas formas de expresión de la opinión pública: en particular, algunos estudios resaltan la posibilidad dialógica que estas plataformas viabilizan entre partidos, referentes públicos, medios informativos tradicionales y ciudadanos. Los discursos de los candidatos en las redes sociales conviven con los discursos políticos de los ciudadanos que, como un elemento central en la historia de la mediatización, disponen de otras formas de acceso y participación, sin los medios tradicionales como intermediarios (Slimovich, 2012). Algunos trabajos con mirada latinoamericana han retomado este potencial democratizador de las redes sociales para los gobiernos 2.0, tanto en lo referente a la ampliación de la participación en el armado de la agenda pública, como en el monitoreo de las políticas que se implementan en las distintas áreas de gestión (Riorda \& Valenti, 2016).

En contrapunto con la mirada anterior, Castro Rojas, Pérezy Amatta (2016) observan cómo los candidatos reforzaron sus comunidades de adherentes, en lugar de propiciar diálogos entre el electorado. Mientras que, desde otra perspectiva, Calvo y Aruguete (2020) siguieron diversas campañas y flujos de dis- 
cusión en torno de tópicos relevantes de la escena política argentina (\#Nisman, \#Tarifazo, \#NiUnaMenos) con el objetivo de decodificar el funcionamiento de las redes sociales en momentos de crisis política y conflicto social.Estos autores ven en Twitter una plataforma que refuerza las posiciones y divisiones políticas existentes en la sociedad y reduce la probabilidad de cruces con opiniones y contenidos diferentes.

En general, los usuarios de Twitter prefieren seguir a los políticos -o a otras figuras de peso- cuya posición ideológica es similar a la suya. En esta línea, Barberá y otros autores (2015) demuestran cómo la decisión de seguir a determinados perfiles nos brinda información sobre las preferencias ideológicas y las proximidades políticas de los usuarios. Siguiendo esta premisa, nos preguntamos cuáles aspectos podemos observar entre las comunidades e internautas que comparten las mismas preferencias ideológicas, y si la acción seguir permite constituir este registro. Los usuarios de Twitter tienen una red declarada de conexiones formada por sus seguidores y una red dinámica, que es la que surge de las interacciones entre ellos (Congosto, 2015). Vale aclarar quelas redes dinámicas son mucho más pequeñas y menos densas quelas redes declaradas.

Como ya comentamos, Slimovich (2018a) propone tres grandes categorías para dar cuenta de las distintas formas de "seguir" en la red: internautasseguidores, internautas-indecisos, internautas-opositores. A su vez, entre los internautas seguidores podemos distinguir entre internautas adherentes, los cuales expresan un perfil más emocional y se enfocan en compartir y ser multiplicadores de contenidos vinculados al partido o candidato al que adhieren, y los internautas militantes, que se caracteriza por ser un grupo al que la autora identifica con un carácter más lógico y activo, con una práctica constante de circulación y producción de contenidos (Slimovich, 2018b).

Asimismo, en el universo general de este tipo de internautas ciudadanos o amateurs conviven los usuarios que representan o son voceros de instituciones políticas (partidos y candidatos) y los internautas profesionales no políticos (periodistas, artistas y otras figuras públicas). Los límites entre este universo y el de los trolls y los bots son difusos, y en este artículo no procuramos delimitar su especificidad, aunque hay tareas concretas que sirven para definir a estos conocidos habitantes de Twitter. Para Calvo (2015), un troll es un "individuo que en forma anónima se dedica a distorsionar la comunicación entre usuarios de una misma comunidad insultando, engañando y atormentando, en algunos casos con objetivos políticos y en otros por el placer sádico de infligir sufrimiento" (p. 105). Mientras que el bot es un software que busca interactuar con los usuarios y replicar comportamientos, por lo cual se trata de una producción de sentido maquinística (Carlón, 2016). De allí que los ingenieros en sistemas hayan desarrollado técnicas para detectar las interferencias que las cuentas automatizadas o bots generan en las conversaciones de Twitter (Ferrara, 2020). 
Por su parte, vale tener en cuenta que el proceso de configuración de identidades y la presentación de la persona en el ciberespacio son aspectos que van de la mano en el análisis de la arquitectura de las redes sociales. Los medios digitales han cultivado nuevos modos de comunicación y personalidad, han reorganizado las percepciones sociales y las formas de autoconciencia, y han establecido intereses colectivos ligados a instituciones y proyectos (Coleman, 2010). Desde su emergencia, las distintas plataformas han desplegado múltiples formas de presentación del símismo (Goffman, 2017) a partir de narrativas del “yo" que, sibien son fragmentadas, dan cuenta de aspectos biográficos delos usuarios. Los perfiles mantienen un yo que despliega su subjetividad a través de la escritura, publicando fotos e imágenes, interviniendo y compartiendo contenido, entre otras acciones digitales. Estas manifestaciones en perfiles individuales se construyen para las biografías en diálogo con los espacios de pertenenciaylasidentificaciones sociales que tengan los usuarios, dando como resultado patrones de presentación propios de cada comunidad en Twitter.

Lovink (2019) refiere al proceso de convertirse en usuario como el aspecto fundamental de este sistema: el acto de crear una cuenta, completar un perfil, elegir nombre de usuario, entre otras formas de configurar el perfil, es a priori "el componente por medio del cual nos convertimos en sujetos en el ciberespacio, sin el cual no pueden operar el perfilamiento ni la publicidad" (p. 56). El perfil es un elemento de expresión identitaria de los usuarios, quienes proporcionan la información textual y visual que permita identificarlos. Completar de un modo u otro esta información requerida por la plataforma supone cierto control del usuario: será él quien decida cuáles datos proporciona y qué expresión identitaria proyectar. Teniendo en cuenta, además, que la cantidad y tipo de información varía según el tipo de red social: en Twitter, por ejemplo, se limita a la imagen de perfil, a la "biografía" de 160 caracteres y al sitio web que uno puede añadir.

Con base en su investigación sobre distintas plataformas, Noblia (2012) establece las categorías semánticas presentes en las descripciones de los internautas: el nombre (adjudicación de nombre o nickname); el cuerpo; la historia de vida o biografía; la subjetividad (sentimientos, emociones, valores, creencias, conocimientos, etc.); y el contexto (lugar, tiempo) particular. También Congosto (2015) muestra que los datos asociados a un perfil de Twitter son muy escasos: el nombre del usuario, su nombre real, su localización, una breve biografía y una URL asociada. Pero solamente son obligatorios los dos primeros, mientras que agregar los demás datos depende de la voluntad de identificarse de cada uno de los usuarios. Aun así, algunos datos demográficos como género, localización geográfica, etnia, pueden inferirse de este perfil tan exiguo, o la edad, la religión y la orientación sexual o la polaridad política.

En síntesis, los internautas se ubican en el espacio social y digital mediante palabras, imágenes, gestos, imaginaciones, deseos, miedos, odios, entre otros 
rasgos. El perfil de Twitter aparece como una superficie de inscripción en la que nos jugamos el yo como un lugar de enunciación. Elyo que se expresa en las redes digitales representa siempre un yo situado en la estructura, y desde cada posición habla una condición política, social, geográfica, de género, religiosa, etc. (Reguillo, 2016).

En el siguiente apartado resumimos las formas de recolección de la información de los usuarios vinculados a la campaña electoral seleccionada para el análisis, las herramientas utilizadas y la visualización de los datos.

\section{DISEÑO Y METODOLOGÍA DE INVESTIGACIÓN}

La era digital abre un nuevo objeto de observación sociológica, que conlleva repensar formas de observar-comprender-investigar las interacciones tecnológicamente mediadas. La problematización de los vínculos, interacciones y narrativas digitales circulantes en Twitter como objeto de investigación requiere la adopción de estrategias metodológicas complementarias, en gran medida provenientes del análisis computacional. A la hora de pensar los estudios digitales Fussey y Roth (2020) sostienen que para la sociología digital la relación teoría-metodología se muestra mucho más intrincada en el proceso de investigación que en otras ramas de la misma disciplina. El desafío consiste en plantear la representatividad offline de las observaciones online y, al mismo tiempo, ser críticos con las limitaciones que plantean los instrumentos (software, apps, plataformas, etc.).

La elección de Twitter como objeto de estudio se basó en el carácter abierto y gratuito de la información que proporciona esta plataforma en comparación con otras redes sociales, tales como Facebook o Instagram (Murthy, 2012). Esta característica permite la descarga de una enorme cantidad de datos semiestructurados en formato Javascript Object Notation (JSON) que pueden obtenerse tanto en flujo directo (streaming), así como del archivo histórico que la red social ofrece a sus usuarios de forma gratuita 4 . Si bien son millones de registros a los que podemos acceder, hay que tener en cuenta que bajo el capitalismo de plataformas la información accesible depende de sus dueños, y estos permisos que la empresa brinda registran cambios en el tiempo (Srnicek, 2018). La limitación más importante a considerar para esta investigación fue la posibilidad de descarga de 75.000 seguidores por perfil (en cierto lapso de tiempo), un número que nos resultó ampliamente holgado por el caudal de followers de los perfiles que seleccionamos.

Para obtener datos en Twitter es necesario poseer una cuenta, luego se registra una aplicación personal (API $)^{\mathbf{5}}$ en Twitter Developer que nos habilita a hacer

4 Se ha comparado con el uso de los métodos que permiten obtener todo el caudal de tweets (statuses/firehose) y la muestra se ha considerado representativa (Morstatter, et al., 2013).

5 Interfaz de programación de aplicaciones. Las API en las redes sociales y en cualquier entorno de programación son métodos a los que se les puede llamar para recoger datos sobre las mismas. 
minería de datos en esta red social. Durante el desarrollo del relevamiento, entre mayo y octubre de 2019, utilizamos la API v.1 de Twitter, en su versión Standard. En este camino de la incipiente programación, para la extracción, procesamiento y análisis de los datos elegimos utilizar el lenguaje R y la aplicación R Studio, un software libre. R es mencionado por la bibliografía recorrida como una herramienta de gran eficacia y su carácter de código abierto permite la colaboración de desarrolladores de todo el mundo. El paquete a utilizar para la extracción y análisis de datos de Twitter fue rtweet. Para el análisis de datos y su visualización se usaron las librerías dplyr, ggplot y wordcloud2, todas disponibles en CRAN ${ }^{6}$.

En este artículo trabajamos con Social Big Data, a partir de la información recolectada para 85655 registros de cuentas de seguidores de candidatos políticos durante la campaña para Intendente en General Pueyrredon, relevados entre mayo yoctubre de 2019. Como ya hemos reseñado en el apartado anterior, el perfil de Twitter está compuesto por una imagen de portada, una imagen, la descripción o "biografía", la ubicación, la cantidad de seguidores, a quiénes sigue el usuario, en qué año se creó la cuenta, cuántas veces faveó publicaciones de otros usuarios.

Luego de identificar los perfiles de los candidatos, construimos una base de datos, compuesta por las cuentas de los seguidores de cada uno de ellos. Para tal fin, extraemos los ids de todos esos usuarios, eliminamos los duplicados y solicitamos -a través de la API- una serie de variables que nos ayudaran en su descripción. En el dataframe que obtenemos, las etiquetas de algunas columnas son: location, friends_count, verified,profile_background_url,description, listed_count, statuses_count, entre otros.

Con este material, en el último apartado de este artículo analizaremos, a partir de algunas técnicas de minería de textos (nube de tags, frecuencia de palabras y correlaciones entre términos), las biografías de seguidores. Con estas herramientas buscamos interpretar el contenido de grandes volúmenes de texto desde una lectura distante (Moretti, 2015). Un paso central para esta aproximación es la limpieza de los textos o lo que también se conoce como la curaduría de los datos. Para obtener mejores resultados realizamos la eliminación de stopwords en español (pronombres, artículos, palabras frecuentes, etc.) y la unificación manual de algunos conceptos similares (por ejemplo, MDP/ Mar del Plata/MDQ).

En este artículo, la nube de palabras es una herramienta de visualización de datos que nos permite aproximarnos a las principales palabras y conceptos que integran la descripción de los perfiles de todos los seguidores de determinado candidato. Al respecto, se han mostrado especialmente útiles para brindar panorámicas en torno a un tema en redes sociales (Khusro, Jabeen \& Khan, 2018). En la nube de descriptores se observan los tamaños de letra proporcionales a la

6 Una parte del trabajo empírico de este artículo se ha realizado a partir de los scripts sugeridos en Salazar (2018). 
importancia numérica (frecuencia) de cada palabra (Hernández Fernández, 2015). Los colores y la distribución se colocan de manera aleatoria. Sus principales desventajas son: por un lado, los vocablos largos atraen más la atención y por otro, es semánticamente ciega.

En diálogo con los aportes teóricos y metodológicos de las investigaciones mencionadas, observemos con un poco más de detalle el proceso eleccionario que hemos seleccionado como caso de estudio.

\section{ELECCIONES 2019. EL CASO DEL PARTIDO DE GENERAL PUEYRREDON}

Para esta investigación nos enfocamos en las elecciones desarrolladas en el PGP, que se encuentra en la provincia de Buenos Aires (Argentina) e integra la quinta sección electoral. Mar del Plata, ciudad cabecera del PGP, es la tercera ciudad más importante de la provincia en cantidad de votantes, después de Matanza y La Plata, capital provincial. Para el 2019, los 573.174 electores habilitados en el PGP emitieron el sufragio para las categorías de presidente, diputados nacionales, gobernador, diputados provinciales e intendente. El proceso electoral se desarrolló en torno a dos momentos: las elecciones Primarias Abiertas Simultáneas y Obligatorias (PASO) durante el 11 de agosto del 2019 y las Elecciones Generales del 27 de octubre del 2019.

Estos comicios se vieron marcados por una fuerte tendencia hacia la polarización política. Uno de los principales contendientes fue el Frente de Todos (FdT), coalición que integraba el Partido Justicialista, los sectores peronistas y no peronistas que se nuclearon en el kirchnerismo ${ }^{7}$ y el Frente Renovador. La otra fuerza relevante, en ese contexto actuando como oficialismo, era Juntos por el Cambio (JxC), espacio de centroderecha que compartían Propuesta Republicana -partido político conocido como PRO-, la Unión Cívica Radical y la Coalición Cívica.

La contienda nacional se definió entre Alberto Fernández-Cristina Kirchner (FdT) y Mauricio Macri-Miguel Ángel Pichetto (JxC). En el plano provincial la puja central enfrentó para el cargo de gobernador a Axel Kicillof (FdT) con María Eugenia Vidal (JxC). Los resultados de las PASO en los niveles superiores dejaron poco espacio para sorpresas en las generales, donde un triunfo de los candidatos del FdT fue casi preanunciado. Pero en General Pueyrredon la disputa mostraba un virtual empate técnico entre dos candidatos. En efecto, el cierre de la elección entre Fernanda Raverta (FdT) y Guillermo Montengro (JxC) fue tan reñido que el FdT cerró su campaña nacional en Mar del Plata, mientras que JxC hizo en la ciudad balnearia su anteúltimo acto de campaña ${ }^{8}$.

7 Corriente política peronista que responde a los liderazgos de Néstor Kirchner, quien fue presidente entre 2003 y 2007, y Cristina Fernández de Kirchner, presidente en períodos sucesivos: 2007-2011 y 2011-2015).

8 Para ampliar la información sobre los cierres de campaña sugerimos las notas: "Macriy Vidal encabezan la marcha del "Sí, se puede" en la ciudad" (Redacción La Capital, 23 de octubre de 2019) y "Raverta: "Esto es una muestra de la importancia de Mar del Plata para el país y la provincia"' (Redacción La Capital, 24 de octubre de 2019). 
El respaldo de los candidatos nacionales y provinciales a los candidatos locales era también clave para evitar la fuga de votos hacia Carlos Arroyo (Agrupación Atlántica), intendente en ese momento y en alianza con Cambiemos desde 2015, y hacia Gustavo Pulti (Acción Marplatense), exintendente y candidato por el kirchnerismo en otras oportunidades.

El peso de la tradición vecinalista en Mar del Plata (Quiroga, 2004; Ferreyra, 2013, Bianchino, 2019) es un aspecto que no puede eludir ningún análisis político. Al igual que en otras oportunidades desde 1983, las elecciones de 2019 se caracterizaron por tener en la competencia electoral figuras políticas provenientes de partidos vecinalistas ${ }^{9}$, con trayectorias centradas en el ámbito municipal, junto a otras figuras que "bajaban" de la política nacional. En este artículo, distinguimos las figuras de Raverta (FdT) y Montenegro (JxC) como candidaturas "nacionalizadas". Ambosocupaban cargos de diputados nacionales en el momento de la campaña, y se ubicaron dentro de fuerzas cuyo armado era transversalen todo el territorio argentino. Se trata de personajes emergentes en la escena local. En el caso del PRO esta estrategia llevo a posicionar como candidato a intendente a Montenegro, quien incluso ya había sido postulado para el mismo cargo en San Isidro durante 2015. Esta situación aparece como excepcional en la historia electoral del PGP desde el regreso de la democracia, ya que los últimos intendentes fueron personas que se habían desempeñado previamente como concejales y/o funcionarios del Ejecutivo Municipal.

Por otra parte, caracterizamos como candidatos vecinalistas o localistas a Pulti, Arroyo y Vilma Baragiola (Unión Cívica Radical-JxC), quienes tienen trayectorias de largo aliento en la política local ${ }^{\mathbf{1 0}}$. Por cierto, este anclaje local no implicó que, dada la creciente nacionalización de la política a partir de 2011 (Freidenberg \& Suárez Cao, 2014), los vecinalismos establecieran alianzas con fuerzas nacionales en distintas oportunidades. Tal como ya señalamos, en 2015 Acción Marplatense hizo un frente con el kirchnerismoy Agrupación Atlántica con el PRO.

No obstante, de cara a las PASO el escenario había sido más nutrido. La competencia se dio entre catorce fuerzas políticas, con sus respectivos precandidatos a intendente, aunque sólo una de ellas disputó una elección interna. De ese total de catorce precandidatos, en este artículo trabajamos con 10, quienes

9 El vecinalismo puede ser entendido, siguiendo a Candia (2001), como organizaciones municipales en torno a las cuales se nuclea el/la vecino/a en tanto sujeto político que está investido de una preocupación por la resolución directa de los problemas más cercanos que afectan a la comunidad, desde el mantenimiento o reparación de equipamiento urbano hasta la construcción de nuevos barrios. Se trata de una forma de organización política que, en principio, estaría desvinculada de las formas políticas tradicionales como los partidos, puesto que encontraría su amalgama en la resolución de problemáticas locales y no en una posición ideológica específica. De este modo, el vecinalismo se vuelve un espacio que convoca a una heterogeneidad de actores, independientemente de su filiación ideológica o partidaria previa. No obstante, conviene recordar que el vecinalismo es un adjetivo para una configuración que, aunque se define como lejos de las ideologías, es ideológica. Una mirada en un sentido contrario implicaría adoptar -de manera ingenua- cierto convencimiento sobre las virtudes de la sociedad civil en oposición a los supuestos vicios de las organizaciones políticas y estatales (Lander, 2002).

10 Un criterio similar de clasificación para analizar la proyección local o nacional de los candidatos encontramos en el informe de la consultora CEPEI (2019). 
tenían una cuenta activa en Twitter al inicio de la campaña (Tabla 1) ${ }^{\mathbf{1 1}}$. Siete precandidatos pasarían a las elecciones generales, al ganar la interna o superar el piso del 1,5\% de los votos, regla instituida para las PASO en la Argentina.

Tabla 1. Precandidatos a intendente para el PGP $2019^{12}$. Se resaltan con negrita aquellos precandidatos que pasaron a las elecciones generales

\begin{tabular}{|l|c|c|c|}
\hline \multicolumn{1}{|c|}{$\begin{array}{c}\text { Nombre del } \\
\text { candidato }\end{array}$} & $\begin{array}{c}\text { Cuenta del candidato } \\
\text { en Twitter }\end{array}$ & $\begin{array}{c}\text { Partido/Espacio } \\
\text { político }\end{array}$ & $\begin{array}{c}\text { Número de seguidores } \\
\text { en Twitter }\end{array}$ \\
\hline Carlos Arroyo & @arroyocf & Agrupación Atlántica & 5.793 \\
\hline Vilma Baragiola & @vilmabaragiola & UCR-JxC & 11.397 \\
\hline Santiago Bonifatti & @SBonifatti & CONSENSO 2030 & 7.154 \\
\hline Alejandro Martínez & @alemilitante & $\begin{array}{c}\text { Partido Obrero-Frente } \\
\text { de Izquierda }\end{array}$ & 1.292 \\
\hline $\begin{array}{l}\text { Guillermo } \\
\text { Montenegro }\end{array}$ & @gmontenegro_ok & PRO-JxC & 36.433 \\
\hline Marcos Pascuan & @MarcosPascuan & Nuevo MAS & 843 \\
\hline Gustavo Pulti & @GustavoPulti & Acción Marplatense & 20.752 \\
\hline Fernanda Raverta & @FerRaverta & FdT & 18.704 \\
\hline Julio Razona & @JulioRazona & Frente Despertar & 699 \\
\hline Marisa Zizmod & @mdpmarisa & Frente NOS & 204 \\
\hline
\end{tabular}

Fuente: elaboración propia con datos extraídos de Twitter en julio 2019.

\section{DIME A QUIÉN SIGUES Y TE DIRÉ QUIÉN ERES}

En este apartado analizamos la composición de seguidores delos 10 precandidatos a intendente que describimos en la Tabla 1 . Al eliminar los duplicados, obtenemos un corpus de $85655^{13}$ cuentas de seguidores de sus perfiles.

A continuación, identificamos la cantidad de cuentas que poseen seguidores en común, niveles de concentración, cruces y distanciamientos existentes entre ellos. En la Tabla 2 observamos que, considerando el total de las cuentas analizadas, el $88 \%$ de los internautas solo siguen a un candidato. El resto de las categorías es sustancialmente menor, siendo que 7,7\% de internautas siguen a dos candidatos, $2,4 \%$ a tres candidatos, y finalmente un $1 \%$ siguen a 4 o más. La preponderancia de los usuarios que siguen sólo a un candidato nos sugiere que la decisión de seguir a un político puede correlacionar positivamente con la posibilidad de votarlo.

11 Los restantes precandidatos fueron: Finamore Marcelo (Movimiento de Organización Democrática), López José Luis (Partido Federal Republicano), Moraiz Cesar (Frente Patriota) y Senno Francisco (Partido Humanista).

12 Para ampliar caracterización de los candidatos, véase la nota titulada: "En Mar del Plata, 14 candidatos y una interna" (Redacción Que Digital, 10 agosto del 2019).

13 Número totalde usuarios, medianteel ID de cada seguidor se contabiliza el total para no duplicar un mismo usuario. 
Tabla 2. Número total y porcentaje de usuarios siguiendo a uno o más precandidatos

\begin{tabular}{|c|c|c|c|c|c|c|c|c|c|c|}
\hline Número de perfiles & $\mathbf{1}$ & $\mathbf{2}$ & $\mathbf{3}$ & $\mathbf{4}$ & $\mathbf{5}$ & $\mathbf{6}$ & $\mathbf{7}$ & $\mathbf{8}$ & $\mathbf{9}$ & $\mathbf{1 0}$ \\
\hline Número de seguidores & 75461 & 6623 & 2079 & 823 & 382 & 188 & 69 & 27 & 2 & 1 \\
\hline$\%$ & 88,1 & 7,7 & 2,4 & 1 & 0,04 & 0,02 & 0,01 & 0 & 0 & 0 \\
\hline
\end{tabular}

Fuente: elaboración propia con datos extraídos de Twitter en julio de 2019. Total: 85655 seguidores.

Pero estos porcentajes varían sustancialmente si desagregamos los seguidores para cada perfil, como se muestra en la Tabla 3 .

Tabla 3. Porcentaje de seguidores únicos o compartidos en Twitter para los candidatos a intendentes 2019 en el PGP

\begin{tabular}{|l|c|c|c|c|c|c|c|c|c|}
\hline \multicolumn{10}{|c|}{ Porcentaje de seguidores entre los candidatos } \\
\hline Candidato & 1 & 2 & 3 & 4 & 5 & 6 & 7 & 8 & 9 \\
\hline Guillermo Montenegro & 91,5 & 5,7 & 2,0 & 0,3 & 0,0 & 0,0 & 0,0 & 0,1 & 0,1 \\
\hline Fernanda Raverta & 85,1 & 8,0 & 3,0 & 2,0 & 1,5 & 0,3 & 0,1 & 0,0 & 0,0 \\
\hline Gustavo Pulti & 68,5 & 17,8 & 7,3 & 3,4 & 1,7 & 0,8 & 0,3 & 0,1 & 0,1 \\
\hline Vilma Baragiola & 50,0 & 25,6 & 13,0 & 6,2 & 3,0 & 1,5 & 0,5 & 0,2 & 0,0 \\
\hline Carlos Fernando Arroyo & 40,3 & 25,2 & 15,2 & 9,2 & 5,3 & 3,0 & 1,2 & 0,4 & 0,2 \\
\hline Santiago Bonifatti & 35,0 & 27,5 & 18,0 & 10,0 & 5,6 & 3,0 & 0,3 & 0,5 & 0,1 \\
\hline Alejandro J. Martínez & 44,5 & 9,7 & 12,0 & 10,5 & 9,0 & 8,5 & 4,0 & 1,7 & 0,1 \\
\hline Marcos Pascuan & 58,7 & 12,0 & 7,5 & 6,6 & 4,3 & 4,5 & 3,7 & 2,4 & 0,2 \\
\hline Julio Razona & 40,7 & 14,4 & 11,0 & 10,0 & 7,0 & 7,5 & 6,0 & 3,1 & 0,2 \\
\hline
\end{tabular}

Fuente: elaboración propia con datos extraídos de Twitter en julio de 2019.

Al diferenciar estos porcentajes para cada uno de los perfiles políticos, en el agrupamiento de las cuentas de seguidores se observan comportamientos diferentes. La mayor concentración aparece en Montenegro, ya que el 91.5\% de las cuentas analizadas solo lo siguen a él. Algo similar ocurre con Raverta, quien registra el $85 \%$ de seguidores exclusivos.

En contraparte, se observa que los candidatos Pulti y Arroyo, a los que habíamos definido como vecinalistas, disminuyen el porcentaje de seguidores propios, correspondiendo el $68,5 \%$ y un $40,5 \%$ a cada uno de ellos. Lo mismo ocurre con figuras que, aunque vinculadas a partidos nacionales, sólo tienen peso en la escena local. Nos referimos a Baragiola, que tiene $50 \%$ de seguidores únicos, y Santiago Bonifatti, alineado con el partido que candidateaba a Roberto Lavagna para presidente (CONSENSO 2030), que apenas roza un 35\% de público propio. Mientras que Alejandro Martínez (Partido Obrero-Frente de Izquierda y los Trabajadores) presenta un 44,5\% de followers que no eligen otros candidatos locales en Twitter, Marcos Pascuan, postulado por el Movimiento al Socialismo, no comparte el 58,7\% de su audiencia. Por su parte, Julio Razona, integrante de una fuerza de ultraderecha (Frente Despertar), hace lo propio con un $40,7 \%$. En concreto, encontramos una diferencia significativa entre la 
dinámica de quienes siguen a candidatos de trayectoria nacional y aquellos que optan por figuras locales. Para los primeros se incrementa la concentración de seguidores propios, mientras que para los segundos se visibilizan mayores solapamientos.

Hilemos todavía un poco más fino mirando la Tabla 4:

Tabla 4. Matriz de coincidencia entre seguidores de los candidatos en el PGP 2019

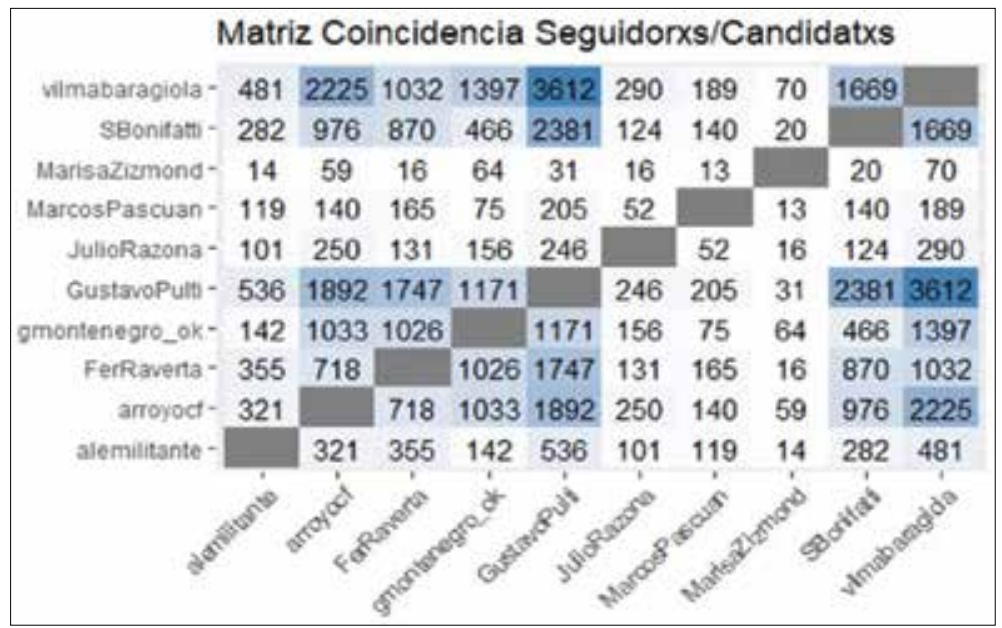

Fuente: elaboración propia. Datos extraídos de agosto de 2019.

En esta tabla, podemos ver entre cuáles candidatos existen yuxtaposiciones de seguidores. Este cruce visibiliza coincidencias esperables entre algunos espacios políticos, Con relación a las preferencias y posicionamientosideológicos e identitarios. Sin embargo, y aquí reside el aporte más interesante, muestra solapamientos menos transparentes.

Raverta comparte pocos seguidores con los demás candidatos, pero registra mayores coincidencias con el público tuitero de Pulti, quien estuvo también vinculado al espacio kirchnerista. El otro candidato fuerte en redes, Montenegro, registra un $10 \%$ de seguidores en común con Baragiola, su competidora en la interna local de JxC. En este caso, ambos cruces muestran coincidencias esperables con relación al espacio político y la adhesión de sus seguidores en términos ideológicos.

Sin embargo, la mayor cantidad de cruces la observamos entre los seguidores de Pulti, Arroyo y Baragiola. En concreto, detectamos cercanías entre los candidatos vecinalistas y de mayor arraigo local, a partir de la frecuencia con que los usuarios deciden seguirlos en forma simultánea. Estos solapamientos de followers son más llamativos, pues ocurren también cuando los perfiles de los candidatos son distantes, o incluso antagónicos, en el plano ideológico. Con 
estos resultados podemos demostrar la existencia de fronteras más permeables entre los seguidores de los políticos en el ámbito local, que permiten la circulación de algunos flujos de información. En esta línea, proponemos la existencia de un espacio público virtual local, un intersticio que escapa a las dinámicas polarizantes, hegemónicas en las redes sociales.

Al respecto, conviene no olvidar que el universo de seguidores de las figuras locales es menor en términos absolutos al que movilizan las figuras nacionales, lo que vuelve su peso específico menos significativo. Otra salvedad importante es quelos ejercicios presentados en este apartado muestran resultados sobre el total del conjunto de seguidores, sin distinciones analíticas entre ellos. Retomando el corpus teórico desplegado al inicio, entendemos que habitan distintos tipos de internautas en este espacio virtual, para los cuales la acción "seguir" en Twitter implica diversos significados. En esta línea, recuperando la clasificación de Slimovich (2018a), podríamos designar a quienes siguen a más de un candidato como internautas indecisos. Arriesgando un poco más, la mayor frecuencia con que estos cruces ocurren entre los seguidores de candidatos locales nos permite proponer la existencia de un internauta-vecino, más interesado por la política local que por los ritmos que imponen las dicotomías políticas a nivel nacional.

Con esta propuesta, en el siguiente apartado abordamos las descripciones biográficas de los perfiles de los seguidores. Nos interesa pensar estos textos como indicadores de narrativas políticas que den cuenta del aspecto identitario, el posicionamiento político, el arraigo local u otras lógicas de la tuitósfera.

\section{BIOGRAFÍAS Y NARRATIVAS POLÍTICAS DE SEGUIDORES}

El análisis de las biografías de los internautas mediante minería de textos nos permitirá empezar a describir un corpus de seguidores que, al inicio, se nos presentaba algo homogéneo. Recordemos que no todos los usuarios poseen descripción, ya que solo una parte de ellos decide escribirla y esto es -como mínimo- un indicador de niveles de participación y actividad en la red. Con base en quienes la poseen, proponemos que las formas de presentación de la persona nos permiten obtener un corpus de datos acerca de su identidad y adscripción a determinado espacio político.

Nos propusimos indagar en las descripciones de biografías como estrategias de autoidentificación para el conjunto de internautas de cada uno de los candidatos, con el objetivo de caracterizar y comparar sus perfiles con base en conceptos, palabras e ideas claves sobre cómo se definen. Problematizamos ¿Cuáles jergas aparecen? ¿Cuáles distancias y similitudes ideológicas hay entre los adeptos de los distintos candidatos con relación a sus narrativas? ¿Cuáles elementos identitarios son afines a cada comunidad de seguidores?

En los gráficos 1, 2, 3 y 4 tomamos las biografías de followers de los candidatos, pero esta vez, sólo nos centraremos en algunos de los que pasaron a las 
TWITTER, INTERNAUTAS VECINOS Y LOS

elecciones generales de octubre. Nos interesa contrastar biografías de seguidores de candidatos "vecinalistas" y "nacionales".

Gráfico 1. Nube de palabras con biografías de seguidores de Fernanda Raverta

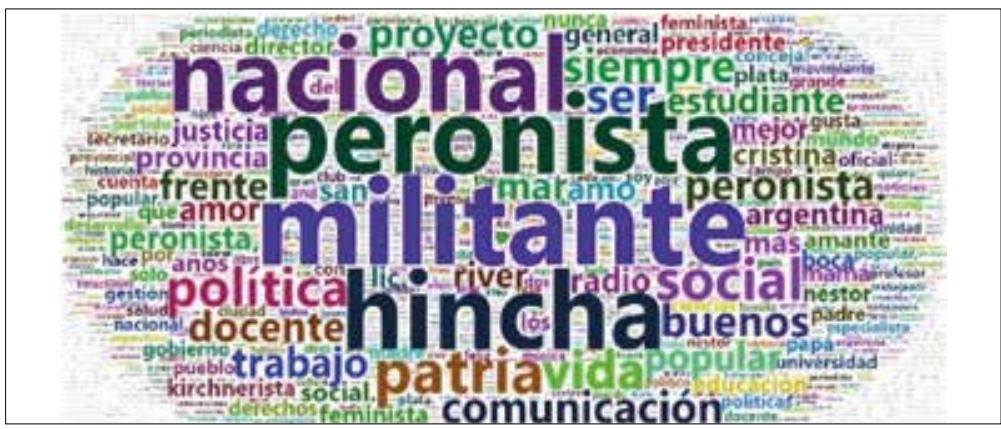

Fuente: elaboración propia, con base en biografías de seguidores descargadas con librería rtweet.

Gráfico 2. Nube de palabras con biografías de seguidores de Guillermo Montenegro

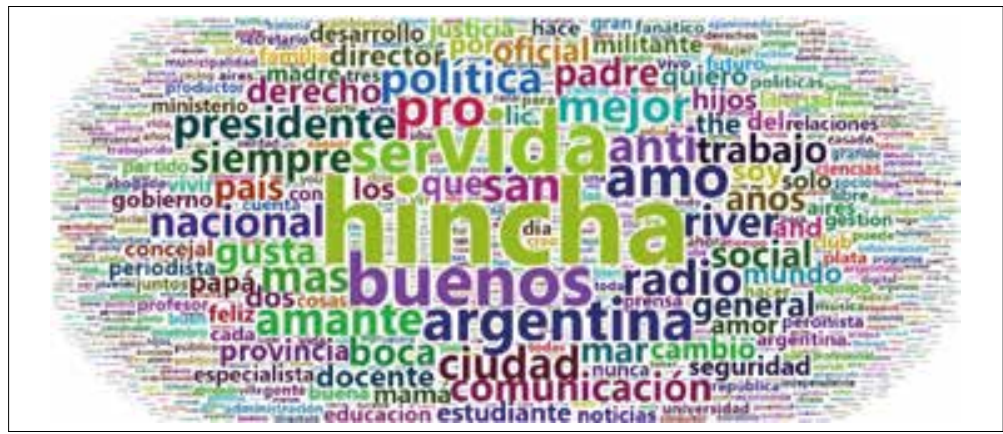

Fuente: elaboración propia, con base en biografías de seguidores descargadas con librería rtweet.

Gráfico 3. Nube de palabras con biografías de seguidores de Gustavo Pulti

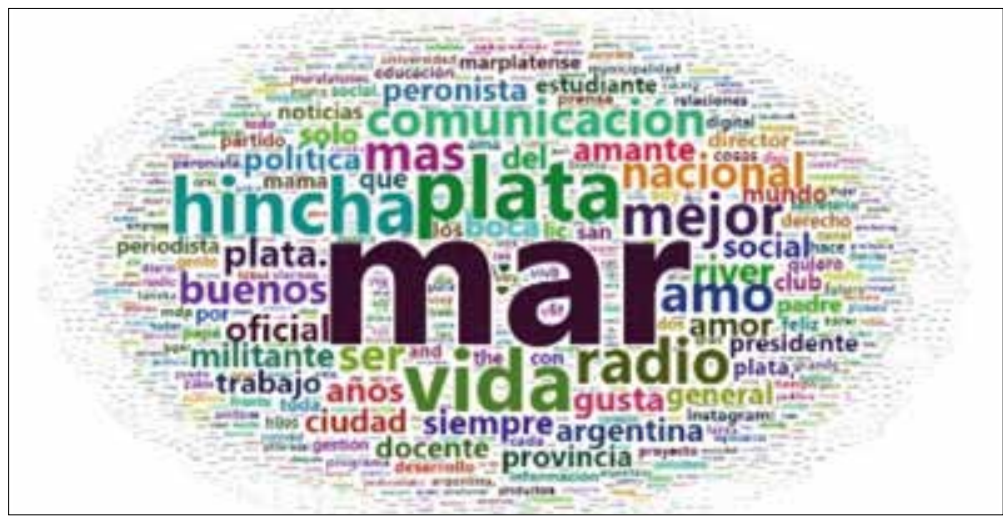

Fuente: elaboración propia, con base en biografías de seguidores descargadas con librería rtweet. 
Gráfico 4. Nube de palabras con biografías de seguidores de Carlos Arroyo

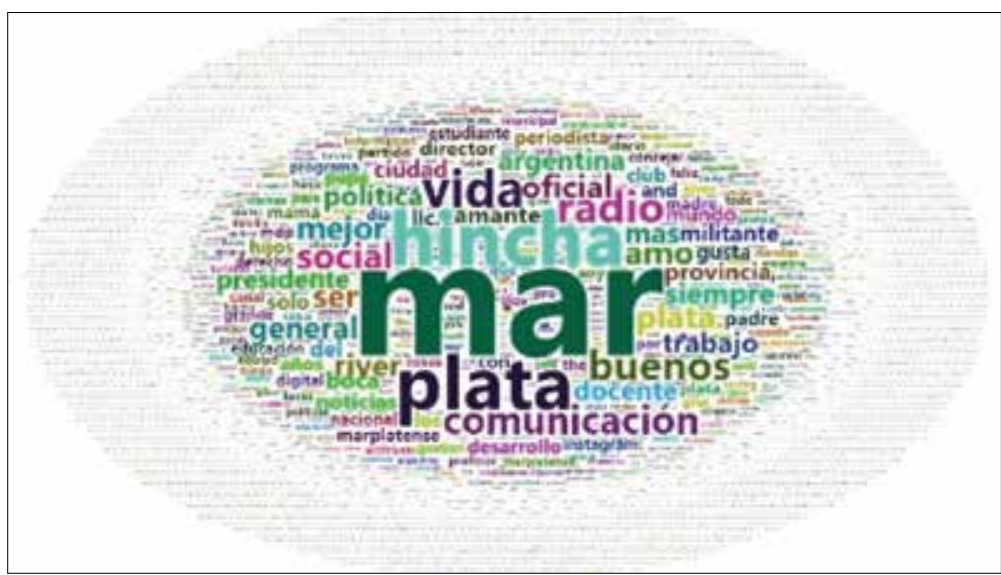

Fuente: elaboración propia, con base en biografías de seguidores descargadas con librería rtweet.

Como señalan Aruguete y Calvo (2018), los usuarios de Twitter no son una muestra representativa de la población en edad de votar, sino una minoría autoseleccionada. En las biografías se observa que quienes participan suelen ser profesionales, docentes, universitarios, políticos, periodistas, organizaciones, entre otros usuarios ubicados en la cima de la pirámide política y cultural. Si bien no todo el mundo conversa en Twitter, creemos que la transmisión de los discursos que aquí se generan hacia otras plataformas masivas, la vuelve significativa para la cultura política del conjunto de los habitantes.

Junto a las referencias ocupacionales, aparecen en la biografía otro tipo de tópicos. Por un lado, referencias acerca de estados emocionales y anímicos, que operan como formas frecuentes de presentación dela persona en el espacio virtual: hincha, mejor, anti, amante/amo, fanático, feliz. Por otrolado, es recurrente destacar el lugar de la familia a partir de descriptores como padre/papa, madre/ mama, hijos, familia, casado.

Como podemos ver en el Gráfico 5, el cuadrante correspondiente a las palabras más frecuentes en las biografías de seguidores de Raverta muestra, en primer lugar, la importancia de la filiación identitaria política. Militante y peronista son los conceptos presentes con mayor frecuencia en las descripciones de estos internautas. En un segundo orden nos encontramos con términos más específicos del espacio político: proyecto, nacional, patria, popular, Cristina, Néstor, kirchnerista. Un tercer grupo está formado por los términos relativos a las referencias ocupacionales, concentrándose en docente, periodista, director, secretario, Lic./licenciado, radio. Otro conjunto se esboza a partir de los términos relativos a conceptos propios de los ejes/agenda política: política, social, comunicación, justicia, feminista, derechos, educación. 
También en el Gráfico 5, pero analizando el diagrama de barras efectuado con base en las frecuencias de palabras en las biografías de los seguidores de Montenegro, el conjunto de palabras referidos a la filiación e identificación del espacio político está presente, aunque en menor frecuencia que para Raverta: presidente, política, pro, cambio, juntos, militante, macri, defensora, anti, peronista, radical. También aparecen conceptos asociados al programa del espacio político Vida (Pro/dos), comunicación, seguridad, derecho, justicia, gestión. Hay una fuerte presencia de descriptores biográficos familiares como padre/papá, madre/ mamá, hijos, familia, casado. Con relación al conjunto de referencias ocupacionales, aparecen nuevas profesiones que no figuraban en la nube de seguidores de la candidata del FdT:abogado, profesor, productor, conductor, consultor, empresas.

Gráfico 5. Palabras más frecuentes en las biografías de seguidores

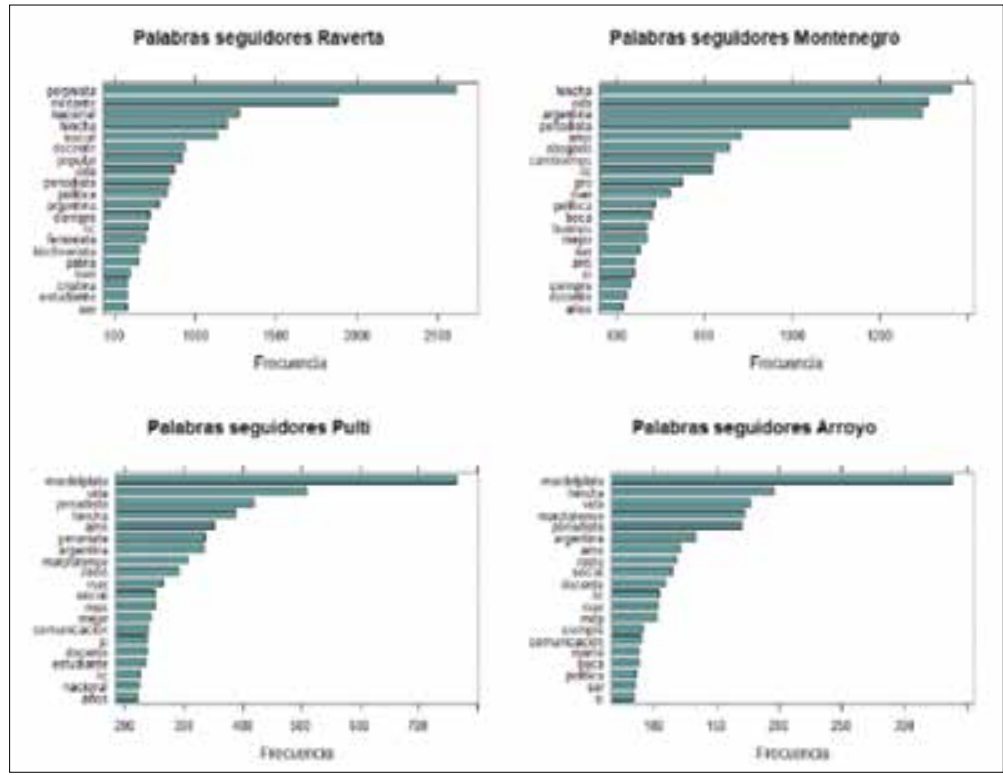

Fuente: elaboración propia.

Los gráficos 6 y 7 muestran las palabras frecuentes únicas para las descripciones de los seguidores de Raverta y Montenegro, mediante cruces entre ambos corpus. Con esta técnica podemos distinguir un núcleo de seguidores, al que preferimos designar como internautas militantes, para aludir al modo en que explicitan su posicionamiento ideológico y su adhesión a un espacio político. En el Gráfico 6visualizamos el uso de slogans propios dela campaña de Juntos por el Cambio: Si se puede, No vuelven más. A la par, aparecen frases que muestra maneras más irónicas de adhesión: el club de los gorilas, chetoslovaquia. En cuanto a la agenda política, conviene resaltar la referencia a la corrupción. 
Gráfico 6. Palabras frecuentes en las biografías de los seguidores de Montenegro que no aparecen en las biografías de los seguidores de Raverta

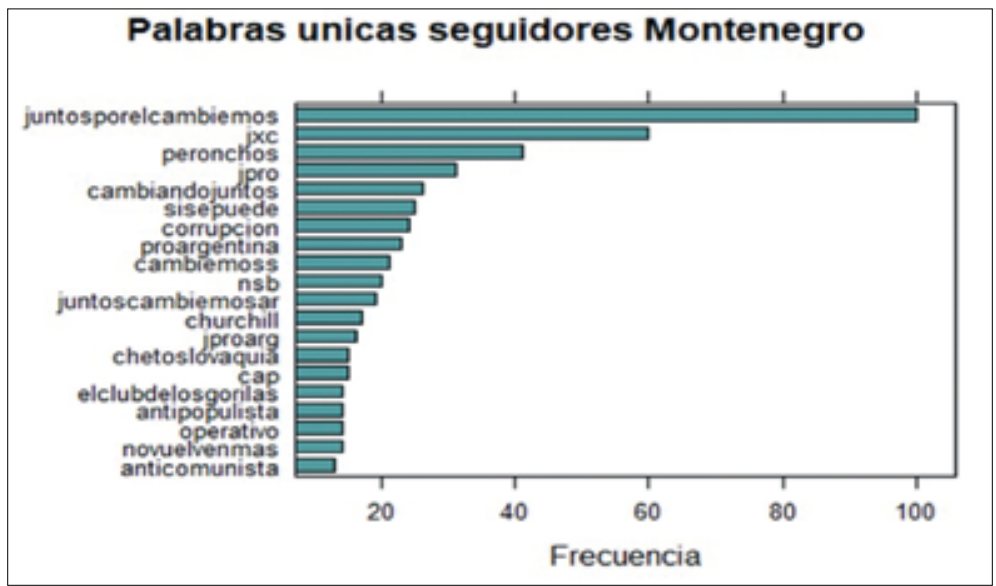

Fuente: elaboración propia.

Al observar, en el Gráfico 7, las palabras únicas de los seguidores de Raverta con respectoa Montenegro, también encontramos slogans de campaña: argentina de pie, la patria es el otro. El mismo gráfico muestra, en primer lugar, la referencia hlvs (Hasta la victoria siempre), comolegado distintivo dela militancia de izquierda. La referencia a géneros, feminismo emerge como singularidad en la agenda de una rama del peronismo más emparentada con posiciones progresistas.

Gráfico 7. Palabras frecuentes en las biografías de los seguidores de Raverta que no aparecen entre las biografías de los seguidores de Montenegro

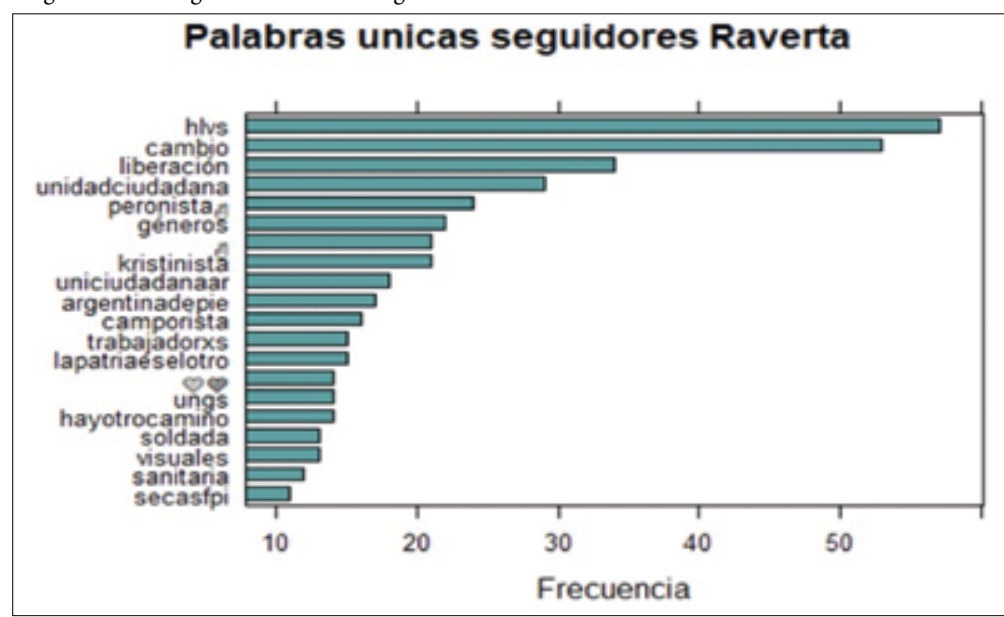

Fuente: elaboración propia. 
En el Gráfico 8 visualizamos de otro modo las palabras más frecuentes de ambos candidatos. Cerca de la línea diagonal se cruzan las palabras de uso común entre ambos conjuntos de seguidores y alejándose las palabras más antagónicas o propias de cada comunidad.

Gráfico 8. Correlación entre las palabras frecuentes de las biografías para cada conjunto de seguidores entre Montenegro y Raverta

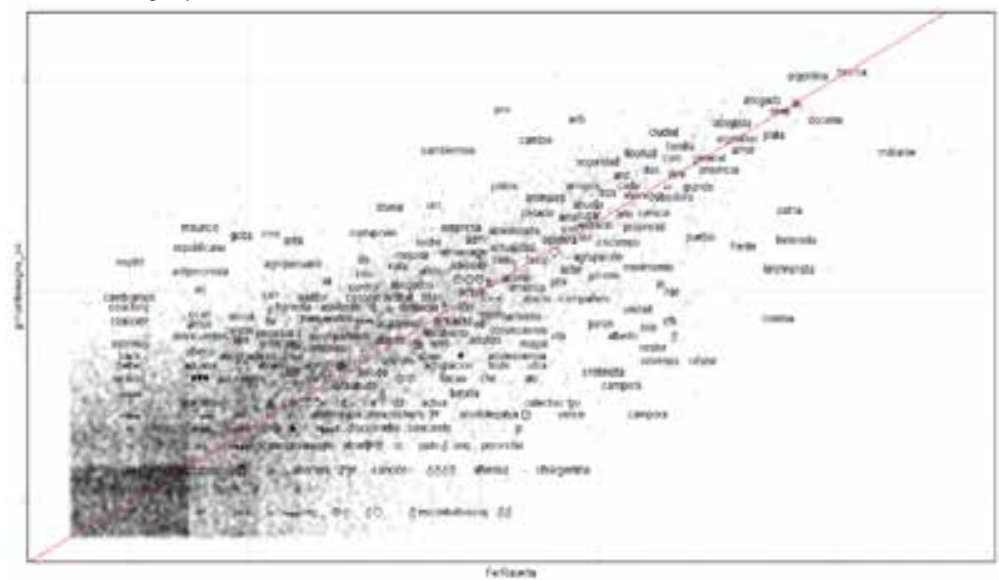

Fuente: elaboración propia.

Para Raverta y Montenegro obtenemos un núcleo de palabras con mayores niveles de politización en las descripciones. ¿Ocurre lo mismo cuando analizamos las biografías de los seguidores de Pulti y Arroyo?

Como ya relatamos, en 2015 Pulti y Arroyo fueron los candidatos a Intendente de frentes muy similares a los que en 2019 cruzaron a Raverta y Montenegro, respectivamente. No obstante, una mirada a sus seguidores refuerza su perfil vecinalista. Al respecto, la ciudad aparece como común denominador principal entre las descripciones de sus seguidores. Los gráficos 3, 4 y 9 muestran la centralidad de la palabra Mar (del Plata), derivaciones como marplatenses, mdp; y otras como municipal, general (Pueyrredon).

Podemos inferir una contextualización más localista en este conjunto de followers como principal dimensión transversal. La presencia de profesiones ligadas a la comunicación y los medios es una constante con los casos ya analizados. Radio, periodista, conductor, diario, información, estudiante, director, docente, UNMDP, son las palabras sobre ocupación más mencionadas. A su vez, observamos con menor frecuencia las referencias a la adscripción política e ideológica en sus biografías.

En esta clave, los followers de candidatos locales parecen "más despolitizados" que los de Raverta y Montenegro. No obstante, nos interesa indagar en los descriptores que brindan indicios de cercanía con algunas de las fuerzas 
nacionales. En el caso de Pulti la presencia de palabras como militante, peronista, PJ, Cristina deja una huella sobre posibles coincidencias con el espacio de Raverta. Mientras que en el caso de Arroyo emergen adscripciones políticas como radical, cambio, anti que muestran algunas coincidencias con el perfil de los seguidores de Montenegro (Gráfico 9).

Gráfico 9. Correlación entre las palabras frecuentes de las biografías para cada conjunto de seguidores entre Arroyo y Pulti

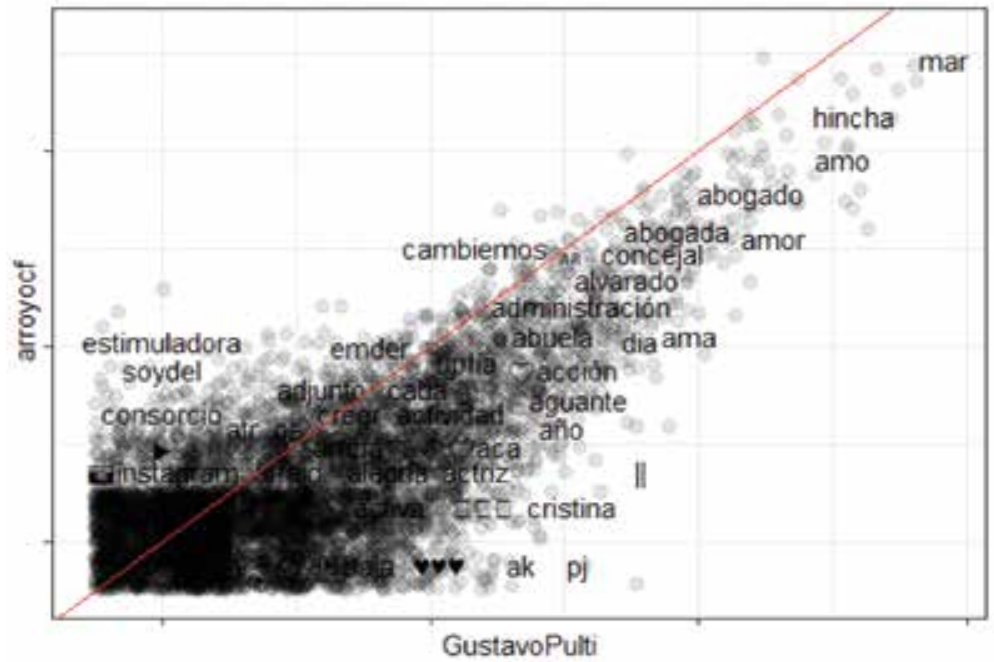

Fuente: elaboración propia.

En resumen, dentro del espacio político virtual que se delinea en torno a los candidatos a intendente, damos cuenta de cuatro tipos de descriptores presentes en las biografías de sus seguidores: ocupacionales, personales, político-ideológicos y geográficos. Las palabras asociadas a la ocupación aparecen en todos los perfiles analizados. Si bien las profesiones vinculadas al mundo de la comunicación y la política son mayoritarias, pueden advertirse algunos perfiles específicos para el público de cada candidato.Los descriptores políticoideológicos son centrales en las narrativas con las que se autodescriben los seguidores de Raverta. Por su parte, los seguidores de Montenegro utilizan de manera más habitual palabras que refieren a cuestiones personales, emociones y familia.

Dentro de la comunidad local encontramos más internautas que centran su descripción en descriptores geográficos y personales. Este núcleo, si bien es menos visible en cantidad de usuarios para el público de los candidatos "nacionalizados", está presente como conjunto de internautas entre distintos candidatos. Su predominio entre los seguidores de candidatos "localistas", nos 
invita a reforzar la tesis sobre la existencia de un espacio público virtual local navegado por internautas-vecinos, menos marcado por tensiones polarizantes, tal como sugería el ejercicio de cruce de seguidores.

\section{REFLEXIONES FINALES}

Este artículo propuso una alternativa original para estudiar campañas electorales en Twitter, al poner el foco en un conjunto de internautas seguidores a candidatos para Intendente en un municipio argentino. En el marco de los debates sobre la existencia de una esfera pública virtual, partimos de un estudio de caso para mostrar la presencia de múltiples espacios públicos en Twitter, que se cruzan y superponen de diversas formas, permitiendo la circulación de flujos de información. El espacio público virtual local aparece como un ejemplo de esos puentes o intersticios que se abren, incluso, en escenarios de alta polarización online y offline.

Para demostrar nuestra hipótesis recorrimos dos caminos: el cruce de seguidores y el análisis textual de sus biografías. Por un lado, comprobamos que muchos usuarios deciden seguir solo a un candidato, lo que indica que el gesto de "seguir" puede interpretarse como una acción potencial para reconocer simpatías y antipatías, en concreto, mostrar preferencias. No obstante, también encontramos cruces entre los seguidores de perfiles de candidatos de distintos signos políticos. Estos solapamientos ocurren con mayor frecuencia entre aquellos candidatos a los que hemos catalogado como vecinalistas, localistas o, más sencillamente, figuras locales. Para caracterizar a ese usuario que sigue varios perfiles locales, hemos propuesto la noción de un internauta-vecino, un tipo de tuitero cuyos intereses lo vinculan con las cuentas que producen contenido en torno a la política local. Por otro lado, a partir del análisis textual de sus biografías, encontramos la presencia de marcadores en torno a la localidad. Ambos hallazgos nos ayudan a delimitar un espacio político local con fronteras permeables y/o zonas grises que podrían atravesar las "cámaras de eco".

Por supuesto, esta brecha no alcanza para frenar la polarización, también visible en este artículo a través del amplio porcentaje de followers que siguen sólo un candidato o de los marcadores ideológicos que encontramos en las biografías de los seguidores de Raverta y Montenegro. En efecto, creemos que las redes pueden incrementar la polarización ideológica e incluso afectar nuestras decisiones políticas (Calvo \& Aruguete, 2020). No obstante, la existencia de un espacio público virtual local y la figura del internauta vecino nos brindan indicios para suponer que la mayor fragmentación no necesariamente implica la consolidación de la polarización. Sin ser excesivamente optimistas, demostramos quelas geografías dela red Twitter también pueden dibujar zonas grises, intersticios que habilitan las discusiones entre distintos posicionamientos $\mathrm{o}$, al menos, organizan timelines con cierta diversidad ideológica. 


\section{REFERENCIAS}

Annunziata, R., Ariza, A. \& March, V. (2017). “Gobernar es estar cerca”. Las estrategias de proximidad en el uso de las redes sociales de Mauricio Macri y María Eugenia Vidal. Revista Mexicana de Opinión Pública, 12(24), 71-93. DOI: http://dx.doi. org/10.22201/fcpys.24484911e.2018.24.61520

Aruguete N. \& Calvo, E. (2018). Política, agendas y redes sociales. Lo que vendrá, 13(10), 302-304.

Barberá, P., Jost, J. T., Nagler, J., Tucker, J. A. \& Bonneau, R. (2015). Tweeting From Left to Right: Is Online Political Communication More Than an Echo Chamber? Psychological Science, 26(10), 1531-1542. DOI: https://doi. org/10.1177/0956797615594620

Bianchino, A.(2019). Vecinalismosentensión. Trayectoriasyarticulacionespara unestudio de las elecciones subnacionales en General Pueyrredon, 2015. Tesis de licenciatura, Universidad Nacional de Mar del Plata, Argentina. Inédita.

Bruns, A. \& Highfield, T. (2018). Is Habermas on Twitter? Social Media and the Public Sphere. In Bruns, A., Skogerbø, E., Christensen, C., Larsson, A. O. \& Enli, G. (Eds.). The Routledge companion to social media and politics (pp. 56-74). New York: Routledge.

Callon, M. (2013). La dinámica de las redes tecno-económicas. En Thomas, H. y Buch, A. (Eds.), Actos, actores y artefactos. Sociología de la tecnología. (pp. 147-184) Bernal: Universidad Nacional de Quilmes.

Calvo E. \& Aruguete N. (2020). Fake news, trolls y otros encantos. Cómo funcionan (para bien y para mal) las redes sociales. Buenos Aires: Siglo Veintiuno.

Calvo, E. (6 de marzo de 2014). Un cafecito para Scioli. El Estadista. Recuperado de: https://www.elestadista.com.ar/?p=4112

Calvo, E. (2015). Anatomía política de Twitter en Argentina. Tuiteando \#Nisman. Buenos Aires: Capital Intelectual.

Candia, J. (2019). Vecinalismo y autogestión. ¿Adiós a los partidos políticos? Estudios Latinoamericanos, 8(15), 35-46. DOI: http://dx.doi.org/10.22201/ cela.24484946e.2001.15.52265

Carlón, M. (2016). Después del fin. Una perspectiva no antropocéntrica sobre la post-tv, el post-cine y YouTube. Buenos Aires: La Crujía.

Castelo, S. (2014). \#PolíticosViolentos. Un análisis de la agresión en el discurso político en Twitter. RevistaSAAP. Publicación de Ciencia Política dela Sociedad Argentina de Análisis Político, 8(2), 609-629. Recuperado de: https://www.redalyc.org/articulo. oa?id=387139302009

Castro Rojas, S., Pérez Rivera, L. \& Amatta, J. (2016). El enjambre digital en la política argentina. Twitter en las campañas 2011-2013-2015. Rizoma, 4(1), 90-104. DOI: https://doi.org/10.17058/rzm.v3i1.6824 
CEPEI (2019) Escenario electoral 2019: políticos nacionales, locales y emergentes. Partido de General Pueyrredon 2019. Recuperado de https://cepeicomunicacion.com/ encuesta/images/pdf/Escenario_electoral_2019_Gral_Pueyrredon_Consultora_ CEPEI.pdf

Coleman, E. G. (2010). Ethnographic Approaches to Digital Media. Annual Review of Anthropology, 39, 487-505. DOI: https://doi.org/10.1146/annurev. anthro.012809.104945

Congosto, M. L. (2015). Elecciones Europeas 2014: viralidad de los mensajes en Twitter Redes: Revista Hispana para el Análisis de Redes Sociales, 26(1),23-52.DOI: https:// doi.org/10.5565/rev/redes.529

Criado, J. I., Martínez-Fuentes, G. \& Silván, A. (2013). Twitter en campaña: las elecciones municipales españolas de 2011. RIPS: Revista De Investigaciones Políticas Y Sociológicas, 12(1).Recuperadode:https://revistas.usc.gal/index.php/rips/article/ view/1307

Ferrara, E. (2020). What types of COVID-19 conspiracies are populated by Twitter bots? First Monday, 25(6). DOI: https://doi.org/10.5210/fm.v25i6.10633

Ferreyra, S. (2013). La descentralización en el proyecto municipal del Partido Socialista Democrático: del imaginario tocquevilliano a las recetas eficientistas (1958- 1966), NuevoMundo, MundosNuevos.DOI:https://doi.org/10.4000/nuevomundo.65386

Fussey, P. \& Roth, S. (2020). Digitizing Sociology: Continuity and Change in the Internet Era. Sociology, 54(4), 659-674. DOI: https://doi.org/10.1177/0038038520918562

Freidenberg, F. \& Suárez Cao, J. (Ed.) (2014). Territorio y Poder: Nuevos actores y competencia política en los sistemas de partidos multinivel en América Latina. Salamanca: Ediciones Universidad de Salamanca.

Galup, L. (2019). Big Data \& Política. De los relatos a los datos, persuadir en la era de las redes sociales. Buenos Aires: Ediciones $\mathrm{B}$.

Goffman, E. (2017). La presentación de la persona en la vida cotidiana. Buenos Aires: Amorrortu.

Hernández Fernández, C. (2015). Nuevos recursos para la investigación cualitativa: Softwaregratuitoyherramientascolaborativas.Opción,31(5),453-471.Recuperado de: https://www.redalyc.org/articulo.oa?id=310/31045570027

Khusro, S., Jabeen, F. \& Khan, A. (2018). Tag Clouds: Past, Present and Future. Proceedings of the National Academy of Sciences, India Section A: Physical Sciences, 91, 369-381. DOI: https://doi.org/10.1007/s40010-018-0571-x

Lander, E. (2002). Sociedad civil ¿Un espacio democrático de los movimientos sociales y del movimiento popular? Utopía y Praxis Latinoamericana, 7(18), 109-115.

Latour, B. (2008). Reensamblarlo social. Una introducción a la teoría del actor-red. Buenos Aires: Manantial.

Lovink, G. (2019). Tristes por diseño. Las redes sociales como ideología. Bilbao: Consoni. 
Moretti, F. (2015). Lectura distante. Buenos Aires: Fondo de Cultura Económica.

Morstatter, F., Pfeffer, J., Liu, H. \& Carley, K. (2013). Is the Sample Good Enough? Comparing Data from Twitter's Streaming API with Twitter's Firehose. In Proceedings of the 7th International Conference on Weblogs and Social Media (pp. 400-408). Cambridge: AAAI Press.

Murthy, D. (2012). Towards a Sociological Understanding of Social Media: Theorizing Twitter. Sociology, 46(6), 1059-1073. DOI: https://doi. org/10.1177/0038038511422553

Noblía, M. V. (2012). La relación interpersonal en el chat. Procesos de construcción y negociación de la identidad. Tesis doctoral, Universidad Nacional de Buenos Aires, Argentina. Inédita.

Papacharissi, Z. (2002). The virtual sphere: The internet as a public sphere. New Media \& Society, 4(1), 9-27. DOI: https://doi.org/10.1177/14614440222226244

Pariser, E. (2011). The filter bubble: What the Internet is hiding from you. New York: Penguin.

Quiroga, N. (2004). El Partido Peronista en Mar del Plata: articulación horizontal y articulación vertical, 1945-1955. Boletín del Instituto de Historia Argentina y Americana Dr. Emilio Ravignani, 26, 75-116.

Redacción Qué Digital (10 de agosto de 2019). En Mar del Plata, 14 candidatos y una interna. Qué Digital. Recuperado de: https://quedigital.com.ar/politica/catorceprecandidatos-y-una-sola-interna-en-mar-del-plata/.

Redacción La Capital (23 de octubre de 2019). Macri y Vidal encabezan la marcha del "Sí, se puede" enla ciudad". La Capital. Recuperado dehttps://www.lacapitalmdp.com/ macri-y-vidal-encabezan-la-marcha-del-si-se-puede-en-la-ciudad/

Redacción La Capital (24 de octubre de 2019). Raverta: "Esto es una muestra de la importancia de Mar del Plata para el país y la provincia”. La Capital. Recuperado de https://www.lacapitalmdp.com/raverta-esto-es-una-muestra-de-laimportancia-de-mar-del-plata-para-el-pais-y-la-provincia/

Reguillo, Rosana. (2017) Paisajes insurrectos. Jóvenes, redes y revueltas en el otoño civilizatorio. Barcelona: Nuevos emprendimientos editoriales.

Riorda, M. \& Valenti, P. (Coords.). (2016). Gobernautas y ciudadanos: los gobernantes latinoamericanos y la gestión de redes sociales. S/R: Banco Interamericano de Desarrollo.

Salazar, C. (2018). Análisis de los seguidores de Twitter de los candidatos presidenciales. RPubs. Recuperado de: https://rpubs.com/camilamila/tweets

Sarlo, B. (2011). La audacia y el cálculo. Kirchner 2003-2010. Buenos Aires: Sudamericana.

Slimovich, A. (2012). El Facebook de los gobernantes. El caso de Cristina Fernández de Kirchner y de Mauricio Macri. En Carlón, M. \& Fausto Neto, A. (Comps.), Las 
políticas de los internautas. Nuevas formas de participación (pp. 137-154). Buenos Aires: La Crujía.

Slimovich, A. (2018a). \#TinelliMercenarioK. La mediatización del presidente argentino y los trolls macristas. InMediaciones de La Comunicación, 13(1), 159-186. DOI: https://doi.org/10.18861/ic.2018.13.1.2830

Slimovich, A. (2018b). El macrismo y la oposición kirchnerista en las redes sociales en la campaña electoral de 2017. RevCom. Revista científica de la Red de Carreras de Comunicación Social, 6, 6-31. Recuperado de: https://perio.unlp.edu.ar/ojs/index. $\mathrm{php} / \mathrm{revcom} /$ article/view/4898

Srnicek, N. (2018). Capitalismo de plataformas. Buenos Aires: Caja Negra.

Van Dijck, J. (2016). La cultura de la conectividad: una historia crítica de las redes sociales. Buenos Aires: Siglo Veintiuno.

Ventura, A. (2016). Argumentación y discurso político en Twitter. Análisis dela campaña presidencial argentina 2011. Aposta. Revista de Ciencias Sociales, 69, 39-66. Recuperado de: https://www.redalyc.org/articulo.oa?id=495952431003

Ventura, A. (2018).¿¿Cómo analizar discursos de 140 caracteres? Propuesta metodológica para el estudio del discurso político de campaña en Twitter a partir del análisis estratégico del discurso con una perspectiva multimodal y crítica. CHIMERA: Romance Corpora and Linguistic Studies, 5(2), 275-287. DOI: http://dx.doi. org/10.15366/chimera2018.5.2.006

${ }^{*}$ Contribución: el trabajo fue organizado de manera conjunta y corresponden porcentajes iguales.

* Nota: el Comité Editorial de la revista aprobó la publicación del artículo.

\section{(cc) BY}

Artículo publicado en acceso abierto bajo la Licencia Creative Commons - Attribution 4.0 International (CC BY 4.0).

\section{IDENTIFICACIÓN DE LAS AUTORAS}

Wanda Juares. Doctora (Cand.), Doctorado de Sociología, Universidad Nacional de San Martín (Argentina). Licenciada en Sociología, Universidad Nacional de Mar del Plata (Argentina). Becaria doctoral, Consejo Nacional de Investigaciones Científicasy Técnicas (Argentina). Integrante, proyecto de investigación "Comunidades virtuales. Historia, prácticas e imaginarios sociales" y del Observatorio Ciudadano Político y Electoral, Universidad Nacional de Mar del Plata (Argentina). Sus temas de interés cruzan el campo político, las representaciones y las narrativas en redes sociales.

Silvana Ferreyra. Doctora en Historia, Universidad Nacional de Mar del Plata (Argentina). Investigadora adjunta, Consejo Nacional de Investigaciones Científicas y Técnicas (Argentina). Codirectora, proyecto de investigación "Comunidades virtuales. Historia, prácticas e imaginarios sociales" y Directora, Observatorio Ciudadano Político y Electora, Universidad Nacional de Mar del Plata (Argentina). Ha publicado diversos libros, capítulos de libros y artículos científicos en los campos de la historia política e intelectual. 
(N) 